\title{
Efeito de diferentes níveis de proteína e energia sobre o rendimento de carcaça de codornas européias
}

[Effect of protein and energy levels on carcass yield of European quails]

\author{
G.S.S. Corrêa ${ }^{1}$, M.A. Silva ${ }^{2}$, D.O. Fontes ${ }^{2}$, A.B. Corrêa ${ }^{1}$, A.C.C. Euler ${ }^{1}$, A.B. Fridrich ${ }^{1}$, \\ I.C. Ferreira ${ }^{1}$, R.V. Ventura ${ }^{1}$, J.E. Rufino ${ }^{1}$, B.D. Valente $^{3}$ \\ ${ }^{1}$ Pós-graduando-EVUFMG - Bolsista do CNPq \\ ${ }^{2}$ Departamento de Zootecnia - Escola de Veterinária da UFMG \\ Caixa Postal 567 \\ 30123-970 - Belo Horizonte, MG \\ ${ }^{3}$ Aluno de graduação - EVUFMG
}

\begin{abstract}
RESUMO
Avaliou-se o rendimento de carcaça de codornas européias de corte (Coturnix coturnix coturnix) no $42^{0}$ dia de idade, alimentadas com dietas contendo quatro níveis de proteína e dois níveis de energia. $\mathrm{O}$ delineamento experimental foi inteiramente ao acaso, com seis repetições e oito codornas por unidade experimental. Os tratamentos constituíram de um fatorial $2 \times 4$, ou seja, dois níveis de energia (2900 e $3100 \mathrm{kcal} \mathrm{EM} / \mathrm{kg}$ ) e quatro níveis de proteína $(22,24,26$ e $28 \%$ proteína bruta na dieta). As variáveis estudadas foram: peso vivo, peso de carcaça, rendimento de carcaça, peso de coxa, rendimento de coxa, peso de peito, rendimento de peito, peso de gordura abdominal, rendimento de gordura abdominal, peso de vísceras comestíveis e rendimento de vísceras comestíveis. Não houve efeito significativo dos níveis de energia e nem dos níveis de proteína sobre nenhuma das características de carcaça analisada.
\end{abstract}

Palavras-chave: codorna, exigência nutricional, rendimento de carcaça

\begin{abstract}
The effect of protein and energy levels on $42^{\text {nd }}$ day carcass yield of European quails (Coturnix coturnix coturnix) was evaluated. A completely randomized design with five replicates and eight quails per experimental unit was used. The treatment consist on diets with two energy metabolic levels (2900 and $3100 \mathrm{kcal} \mathrm{EM} / \mathrm{kg})$ and four protein levels $(22,24,26$ and $28 \%$ of crude protein). The traits analyzed were body weight and weight and yield of carcass, tight, breast, fat and edible viscera. No significant effects of crude protein and metabolic energy levels on carcass traits were found.
\end{abstract}

Keywords: quail, nutritional requirement, carcass yield

Recebido para publicação em 29 de fevereiro de 2004

Recebido para publicação, após modificações, em 16 de dezembro de 2004

* Autor para correspondência (corresponding author)

E-mail: martinho@vet.ufmg.br 


\section{INTRODUÇÃO}

No Brasil, as codornas são comercializadas em embalagens com aproximadamente cinco carcaças congeladas, de peso médio de $200 \mathrm{~g}$. Nos Estados Unidos, além desse tipo de carcaça, são também comercializadas codornas desossadas, da espécie Bobwhite, com pesos de até 300 gramas pós-processamento (Murakami e Joji, 1998).

Hamm et al. (1982), ao compararem o peso, o rendimento de carcaça e a composição da carcaça de codornas Japonesa, Bobwhite e Bobwhite selvagem, observaram que a Bobwhite apresentou maior peso vivo, melhor rendimento de carcaça, maior percentagem de músculo de peito e maior percentagem de carne, em relação às demais. A Bobwhite e a codorna selvagem apresentaram maior teor de proteína e a Japonesa maior percentagem de gordura na carcaça.

Rajini e Narahari (1998) compararam o desempenho de codornas em crescimento, alimentadas com rações contendo 24,26 e $28 \%$ de proteína entre 0 e 3 semanas e 18,20 e $22 \%$ entre quatro e seis semanas de idade, e níveis de energia metabolizável de 2400, 2600 e $2800 \mathrm{kcal} / \mathrm{kg}$ nos mesmos períodos. Verificaram que $28 \%$ de proteína bruta na fase inicial e $22 \%$, na fase final, resultaram em maior rendimento de carcaça, maior percentagem de proteína e menor percentagem de gordura na carcaça, enquanto que o maior nível de energia resultou em menor teor de proteínas e maior de gordura na carcaça.

O material genético disponível para produção de codornas para carne no Brasil é pouco adequado em razão da utilização de codornas japonesas ou "italianas", selecionadas para a produção de ovos. Elas são aves com características pouco adequadas para a produção de carne. Assim, há necessidade de se obter material genético especializado, com maior peso e melhor conformação de carcaça, ideais para o atendimento dos mercados interno e de exportação (Garcia, 2002).

Vários trabalhos têm indicado diferença nas exigências nutricionais entre grupos genéticos para características de desempenho. No entanto, não existem informações disponíveis quanto as características de carcaça de codornas criadas para corte. Assim, este experimento foi realizado com o objetivo de comparar o rendimento de carcaça, no $42^{0}$ dia de idade, de codornas machos (Coturnix coturnix coturnix), alimentadas com dietas contendo diferentes níveis de proteína e de energia.

\section{MATERIAL E MÉTODOS}

No experimento, com duração de 42 dias, foram utilizadas 384 codornas européias de corte, machos, com sete dias de idade, em delineamento inteiramente ao acaso, em esquema fatorial $4 \times 2(22,24,26$ e $28 \%$ de PB e 2900 e $3100 \mathrm{kcal} \mathrm{EM} / \mathrm{kg}$ ), com seis repetições e oito aves por unidade experimental.

As aves, alojadas em baterias metálicas medindo $0,82 \mathrm{~m}$ de largura $\mathrm{x} 0,41 \mathrm{~m}$ de profundidade $\mathrm{x}$ $0,27 \mathrm{~m}$ de altura por divisão, receberam água $\mathrm{e}$ ração à vontade. Os ingredientes e a composição das rações experimentais são apresentados na Tab. 1.

As dietas foram formuladas de acordo com a composição dos ingredientes apresentada por Rostagno et al. (2000). Para os demais nutrientes, as exigências basearam-se no Nutrient... (1994).

No $42^{0}$ dia de idade, após jejum de sólidos de oito horas, três aves por unidade experimental foram individualmente pesadas, marcadas por meio de lacres em forma de anéis em um dos pés e abatidas. A seguir, foram depenadas, evisceradas e submetidas aos cortes para avaliações do rendimento de carcaça em relação ao peso vivo e do rendimento de peito e pernas em relação ao peso da carcaça. Foram estudados: peso vivo, peso e rendimento da carcaça, peso e rendimento da coxa (coxa mais sobrecoxa), peso e rendimento de peito, peso e rendimento da gordura abdominal e peso e rendimento de vísceras comestíveis (fígado, moela e coração).

Todas as análises estatísticas foram efetuadas usando-se o programa SAEG (Sistema..., 2001).

\section{RESULTADOS E DISCUSSÃO}

Os resultados de rendimento de carcaça e das partes em relação ao peso vivo são apresentados na Tab. 2. Não foram encontrados efeitos dos níveis de energia e de proteína sobre as variáveis estudadas. Contudo, as codornas mostraram desempenho satisfatório de peso quando alimentadas com as dietas contendo os níveis 


\section{Corrêa et al.}

mais baixos de energia e proteína, o que representou menor custo de produção. $\mathrm{O}$ desempenho da codorna no nível de proteína de $22 \%$ é menor do que o de $24 \%$ recomendado pelo Nutrient... (1977). Freitas et al. (2003) relataram resultados semelhantes sobre o peso de codornas de corte nos níveis de 20 a $26 \%$ de proteína e de 2700 a $3150 \mathrm{kcal} \mathrm{EM} / \mathrm{kg}$.

Tabela 1. Composição das dietas experimentais utilizadas para codornas de corte do $7^{0}$ ao $42^{0}$ dia de idade, de acordo com os tratamentos

\begin{tabular}{|c|c|c|c|c|c|c|c|c|}
\hline \multirow{3}{*}{ Ingrediente $(\%)$} & \multicolumn{4}{|c|}{ 2900kcal EM/kg } & \multicolumn{4}{|c|}{ 3100kcal EM/kg } \\
\hline & \multicolumn{4}{|c|}{ Proteína bruta (\%) } & \multicolumn{4}{|c|}{ Proteína bruta $(\%)$} \\
\hline & 22 & 24 & 26 & 28 & 22 & 24 & 26 & 28 \\
\hline Milho & 53,60 & 47,08 & 40,56 & 34,03 & 53,44 & 46,91 & 40,39 & 33,87 \\
\hline Farelo de soja & 36,54 & 42,05 & 47,56 & 53,07 & 37,64 & 43,15 & 48,66 & 54,17 \\
\hline Farelo de trigo & 4,00 & 4,00 & 4,00 & 4,00 & 1,00 & 1,00 & 1,00 & 1,00 \\
\hline Óleo de soja & 2,60 & 3,66 & 4,73 & 5,80 & 4,64 & 5,71 & 6,78 & 7,84 \\
\hline Calcário & 1,11 & 1,08 & 1,06 & 1,04 & 1,09 & 1,06 & 1,04 & 1,02 \\
\hline Fosfato bicálcico & 0,95 & 0,92 & 0,90 & 0,86 & 0,99 & 0,96 & 0,93 & 0,90 \\
\hline Suplemento mineral e vitamínico $^{1}$ & 0,50 & 0,50 & 0,50 & 0,50 & 0,50 & 0,50 & 0,50 & 0,50 \\
\hline Sal comum & 0,27 & 0,27 & 0,26 & 0,25 & 0,27 & 0,27 & 0,26 & 0,26 \\
\hline DL- metionina & 0,09 & 0,14 & 0,18 & 0,23 & 0,10 & 0,15 & 0,19 & 0,24 \\
\hline L-treonina & 0,07 & 0,10 & 0,13 & 0,16 & 0,07 & 0,11 & 0,14 & 0,17 \\
\hline Inerte & 0,27 & 0,20 & 0,12 & 0,05 & 0,26 & 0,18 & 0,11 & 0,03 \\
\hline Total & 100,00 & 100,00 & 100,00 & 100,00 & 100,00 & 100,00 & 100,00 & 100,00 \\
\hline \multicolumn{9}{|l|}{ Composição calculada } \\
\hline Proteína bruta $(\%)$ & 22,00 & 24,00 & 26,00 & 28,00 & 22,00 & 24,00 & 26,00 & 28,00 \\
\hline EM (kcal/kg) & 2900 & 2900 & 2900 & 2900 & 3100 & 3100 & 3100 & 3100 \\
\hline Cálcio (\%) & 0,80 & 0,80 & 0,80 & 0,80 & 0,80 & 0,80 & 0,80 & 0,80 \\
\hline Fósforo disponível (\%) & 0,30 & 0,30 & 0,30 & 0,30 & 0,30 & 0,30 & 0,30 & 0,30 \\
\hline Metionina+Cistina( $(\%)$ & 0,78 & 0,87 & 0,96 & 1,05 & 0,78 & 0,87 & 0,96 & 1,05 \\
\hline Metionina (\%) & 0,53 & 0,60 & 0,67 & 0,74 & 0,54 & 0,61 & 0,68 & 0,75 \\
\hline Lisina $(\%)$ & 1,17 & 1,31 & 1,45 & 1,59 & 1,19 & 1,32 & 1,46 & 1,60 \\
\hline Treonina $(\%)$ & 0,92 & 1,02 & 1,13 & 1,24 & 0,92 & 1,03 & 1,14 & 1,25 \\
\hline
\end{tabular}

Edwards (1981) recomendou para codornas japonesas nível de $30 \%$ de proteína na dieta para machos e fêmeas. $\mathrm{O}$ autor observou que $\mathrm{o}$ aumento no nível de proteína da dieta resultou em taxa de crescimento mais rápida do que os observados em níveis de proteína mais baixos.

Conforme Shim e Vohra (1984), as exigências nutricionais de codornas são maiores do que as de galinhas poedeiras. Possivelmente a maior atividade física das codornas quando comparada à das galinhas poedeiras pode explicar as exigências mais altas em proteína e energia. Vohra (1971), em revisão de nutrição de codornas, verificou que níveis de $25 \%$ são necessários para maior desempenho de codornas japonesas. Roush et al. (1979), ao determinarem o nível ótimo de proteína e energia metabolizável nas dietas de codornas japonesas para a máxima taxa de crescimento, observaram melhor desempenho no nível de $30 \%$ de proteína bruta e $2743 \mathrm{kcal}$ EM/kg de ração. Sakurai (1971) verificou que as codornas apresentaram máximo ganho de peso em dietas com 32,2\% de PB e $3100 \mathrm{kcal} \mathrm{EM} / \mathrm{kg}$ de ração, enquanto que Oliveira et al. (2002) observaram efeito linear positivo dos níveis de proteína bruta sobre o ganho de peso acumulado nos níveis 2800 e $3000 \mathrm{kcal}$ $\mathrm{EM} / \mathrm{kg}$ de ração. Nesses níveis, os autores encontraram maior peso nos machos alimentados com dietas contendo $26 \%$ de PB e $3200 \mathrm{kcal}$ $\mathrm{EM} / \mathrm{kg}$ de ração.

Os resultados de peso corporal na quinta semana observados por Webwe e Reid (1967) e na quarta semana de idade por Lepore e Marks (1971) indicaram que as codornas na fase inicial de crescimento precisam de $25 \%$ de proteína bruta. Lee et al. (1977), ao trabalharem com exigências protéicas de codornas japonesas em crescimento nos trópicos, indicaram nível de 28-32\% de PB.

Panda e Shrivastav (1978) indicaram exigência ligeiramente maior para codornas na fase inicial 
Efeito de diferentes níveis de proteína...

(27\%), conteúdo que pode ser diminuído após três semanas de idade. Segundo Shrivastav (2003), é possível explicar esse aumento nas exigências iniciais pela inadequação dos aminoácidos e do estresse calórico.

Tabela 2. Característica de carcaça de codornas de corte alimentadas com dietas contendo diferentes níveis de proteína e energia

\begin{tabular}{|c|c|c|c|c|}
\hline \multirow{2}{*}{ Variável } & \multirow{2}{*}{$\begin{array}{l}\text { Proteína } \\
\text { bruta }(\%)\end{array}$} & \multicolumn{2}{|c|}{ Energia metabolizável (kcal/kg) } & \multirow{2}{*}{$\begin{array}{l}\text { CV } \\
(\%)\end{array}$} \\
\hline & & 2900 & 3100 & \\
\hline \multirow{4}{*}{ Peso vivo (g) } & 22 & 239,44 & 246,05 & \multirow{4}{*}{7,05} \\
\hline & 24 & 244,36 & 243,11 & \\
\hline & 26 & 248,00 & 256,52 & \\
\hline & 28 & 243,94 & 256,33 & \\
\hline \multirow{4}{*}{ Peso da carcaça (g) } & 22 & 177,83 & 181,17 & \multirow{4}{*}{6,75} \\
\hline & 24 & 183,30 & 182,03 & \\
\hline & 26 & 183,28 & 185,28 & \\
\hline & 28 & 181,80 & 188,03 & \\
\hline \multirow{4}{*}{ Rendimento da carcaça (\%) } & 22 & 74,28 & 73,63 & \multirow{4}{*}{2,46} \\
\hline & 24 & 75,03 & 74,86 & \\
\hline & 26 & 73,99 & 72,27 & \\
\hline & 28 & 74,57 & 73,39 & \\
\hline \multirow{4}{*}{ Peso de coxa (g) } & 22 & 41,92 & 41,64 & \multirow{4}{*}{7,38} \\
\hline & 24 & 42,25 & 43,36 & \\
\hline & 26 & 44,67 & 43,31 & \\
\hline & 28 & 42,75 & 44,55 & \\
\hline \multirow{4}{*}{ Rendimento da coxa (\%) } & 22 & 17,52 & 16,96 & \multirow{4}{*}{5,67} \\
\hline & 24 & 17,30 & 17,83 & \\
\hline & 26 & 18,02 & 16,90 & \\
\hline & 28 & 17,59 & 17,40 & \\
\hline \multirow{4}{*}{ Peso do peito (g) } & 22 & 67,08 & 66,53 & \multirow{4}{*}{12,44} \\
\hline & 24 & 67,61 & 63,36 & \\
\hline & 26 & 65,61 & 68,14 & \\
\hline & 28 & 67,83 & 67,08 & \\
\hline \multirow{4}{*}{ Rendimento do peito (\%) } & 22 & 27,99 & 27,09 & \multirow{4}{*}{10,47} \\
\hline & 24 & 27,73 & 25,92 & \\
\hline & 26 & 26,46 & 26,59 & \\
\hline & 28 & 27,77 & 26,24 & \\
\hline \multirow{4}{*}{$\begin{array}{l}\text { Peso da gordura abdominal } \\
(\mathrm{g})\end{array}$} & 22 & 3,19 & 4,53 & \multirow{4}{*}{70,13} \\
\hline & 24 & 3,98 & 4,14 & \\
\hline & 26 & 3,39 & 4,33 & \\
\hline & 28 & 2,64 & 4,50 & \\
\hline \multirow{4}{*}{$\begin{array}{l}\text { Rendimento da gordura } \\
\text { abdominal (\%) }\end{array}$} & 22 & 1,31 & 1,80 & \multirow{4}{*}{65,55} \\
\hline & 24 & 1,61 & 1,62 & \\
\hline & 26 & 1,33 & 1,65 & \\
\hline & 28 & 1,07 & 1,75 & \\
\hline \multirow{4}{*}{$\begin{array}{l}\text { Peso das vísceras } \\
\text { comestíveis }(\mathrm{g})\end{array}$} & 22 & 9,83 & 9,69 & \multirow{4}{*}{14,11} \\
\hline & 24 & 9,67 & 9,78 & \\
\hline & 26 & 10,11 & 10,67 & \\
\hline & 28 & 9,64 & 10,36 & \\
\hline & 22 & 4,12 & 3,94 & \\
\hline & 24 & 3,95 & 4,02 & 12,52 \\
\hline $\begin{array}{l}\text { Rendimento das visceras } \\
\text { comestíveis }(\%)\end{array}$ & 26 & 4,07 & 4,13 & \\
\hline comestivers (70) & 28 & 3,99 & 4,04 & \\
\hline
\end{tabular}

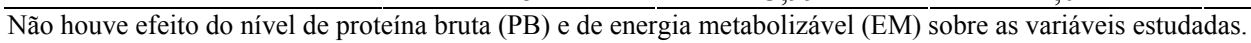


Shrivastav e Panda (1991), ao estudarem a variação na taxa de crescimento, qualidade de carne e possibilidade do mercado de codornas, associados com o conteúdo de proteína da dieta, relataram declínio na taxa de crescimento após a quinta semana, independente do conteúdo de proteína da dieta. Os autores citaram que os valores máximos de peso, rendimento de carne e lucro sobre o custo da ração aconteceram na quinta semana de idade, e que o desempenho máximo foi alcançado com a dieta contendo $27 \%$ de PB.

Mishra et al. (1993) indicaram que dietas com 24\% PB, suplementadas com aminoácidos (metionina e lisina) foram tão eficientes quanto aquelas com $27 \%$ PB para as características de crescimento. Marks (1978) revelou que o ganho de peso de codornas Japonesas, de ambos os sexos e alimentadas com dietas contendo $20 \%$ PB foi de 96 a 99\%, menor que o de codornas alimentadas com $28 \%$ de PB.

\section{CONCLUSÕES}

Os níveis de proteína bruta e energia metabolizável utilizados nas dietas não foram suficientes para promover alterações significativas nas características de carcaça de codornas de corte.

\section{REFERÊNCIAS BIBLIOGRÁFICAS}

EDWARDS, H.M. Jr. Carcass composition studies. 3. Influence of age sex and calorie protein content of the diet on carcass composition of japonese quail. Poult. Sci., v.60, p.2506-2512, 1981.

FREITAS, A.C.; FUENTES, M.F.F.; FACÓ, O. et al. Efeito de diferentes níveis de proteína e energia para codornas de corte em clima tropical. In: REUNIÃO ANUAL DA SOCIEDADE BRASILEIRA DE ZOOTECNIA, 40., 2003, Santa Maria, RS. Anais... Santa Maria: SBZ, 2003. (CD-ROM).

GARCIA, E.A. Codornas para produção de carne. SIMPÓSIO INTERNACIONAL DE COTURNICULTURA - Novos Conceitos Aplicados à Criação de Codornas, 2002, Lavras. Anais... Lavras, 2002.
HAMM, D.; ANG, C.Y.W. Nutrient composition of quail meat from three soucers. J. Food Sci., v.47, p.1613-1614, 1982.

LEE, T.K.; SKIM, K.F.; TAN, E.L. Protein requeriment of growing Japonese quail in the tropics. Singap. J. Prim. Industr., v.5, p.70, 1977.

LEPORE, R.D.; MARKS, H.L. Growth rate inheritance in Japonese quail 5. Protein and energy requeriments of lines selected under different nutritional environments. Poult. Sci., v.50, p.1335-1341, 1971.

MARKS, H.L. Compensatory growth in Japonese quail following protein restriction. Poult. Sci., v.57, p.1473-1477, 1978.

MARKS, H.L. Evoluation of growth selected quail lines under different nutritional environments. Poult. Sci., v.50, p.17531761,1971 .

MISHRA, S.K.; PANDA, B.; MOHAPATRA, S.C. et al. Response of genotype to dietary protein levels for growth and carcass quality traits in Japonese quail. Indian J. Poult. Sci., v.28, p.106-115, 1993.

MURAKAMI, A.E.; ARIKI, J. Produção de codornas japonesas. Jaboticabal: FUNEP, 1998. $79 \mathrm{p}$.

NUTRIENT requirements of poultry. 9.ed. Washington: National Academic, 1994. 156p.

NUTRIENT requirements of poultry. Washington: NRC, 1977.

OLIVEIRA, N.T.E; SILVA, M.A.; SOARES, R.J.R.N. et al. Exigências de proteína bruta e energia metabolizável para codornas japonesas criadas para a produção de carne. Rev. Bras. Zootec., v.31, p.657-686, 2002.

PANDA, B.; SHRIVASTAV, A.K. Protein requeriment of starter Japonese quail. WORLD 'S POULTRY CONGRESS, 16., 1978, Rio de Janeiro. Proceedings... Rio de Janeiro, 1978. p. 1347

RAJINI, R.A.; NARAHARI, D. Dietary energy abd protein requeriments od growing japonese quails in the tropics. Indian J. Anim. Sci., v.68, p.1082-1086, 1998.

ROSTAGNO. H.S.; SILVA, D.J.; COSTA, P.M.A. et al. Composição de alimentos e exigências nutricionais de aves e suínos (Tabelas 
Brasileiras). Viçosa: Universidade Federal de Viçosa, 2000. 141p.

ROUSH, W.B.; R.S. PETERSON, ARSCOTT, G.H. An apllication of response surface methodology to research $\mathrm{n}$ poultry in poultry nutrition. Poult. Sci., v.58, p.1504-1513, 1979.

SAKURAI, H. Influence of dietary levels of protein and enrgy on nitrogen and energy balance for egg production of Japonese quail. Jpn. Poult. Sci., v.18, p.185-190, 1981.

SHIM, K.F.;VOHRA, P. A review of the nutrition of Japonese quail. World's Poult. Sci. J., v.40, p.261-374, 1984.

SHRIVASTAV, A.K.; PANDA, B. Effect of age and diet on growth, meat quality and market possibilities of Japonese quail broilers. Indian Vet. Med. J., v.15, p.25-33, 1991.

SHRIVASTAV, A.K.; PANDA, B. Effect of dietary calories to protein ratio at different energy concentration on the performance of broilers quails. Indian J. Poult Sci., v.25, p.7987, 1990.

SHRIVASTAV, A.K. Recentes avanços na nutrição de codornas japonesas. SIMPÓSIO INTERNACIONAL DE COTURNICULTURA - Novos Conceitos Aplicados à Criação de Codornas, Lavras. Anais... Lavras, 2002.

SISTEMA de análises estatísticas e genéticas SAEG. Viçosa, MG: UFV, 2001. 301p. (Manual do usuário)

VOHRA, P. A review of the nutrition of Japonese quail. World's Poult. Sci., v.27, p.2634, 1971.

WEBWE, C.W.; REID, B.L. Poultry requeriments of coturnix quail to five weeks of age. Poult. Sci., v.46, p.1190-1194, 1967. 